\title{
Ética e valores na formação profissional em saúde: um estudo de caso
}

\author{
Ethics and values in professional training in health: a case study
}

Mirelle Finkler ${ }^{1}$

João Carlos Caetano ${ }^{1}$

Flávia Regina Souza Ramos ${ }^{2}$

${ }^{1}$ Programa de PósGraduação em Odontologia, Universidade Federal de Santa Catarina. Campus Universitário, Trindade. 88.040-970 Florianópolis SC.

mirellefinkler@yahoo.com.br ${ }^{2}$ Programa de Pós-

Graduação em Enfermagem, Universidade Federal de Santa Catarina.

\begin{abstract}
The scope of this research was to analyze the ethical dimension of the training of health professionals, specifically in Dentistry. Interviews were conducted with teachers, in addition to observation of academic activities and focus groups with students of two undergraduate courses. Data analysis revealed some elements of the hidden curriculum that influences the ethical dimension of training. The results discussed here suggest different ethical concepts in the academic environment with the predominance of an implicit code of ethics, the consequences of which require attention in the management of daily ethical conflicts. Based on common sense and a lack of intentionality of the academic staff with respect to the ethical training of students, it is imperative to know the values they cherish in order to understand their moral development and identify a bioethical benchmark upon which the pedagogicalethical issue is grounded. By way of conclusion, it is essential to assume individual and collective teaching responsibility for the ethical dimension of training in order that the professional training also has the potential for the integrated training of the human being as a whole.
\end{abstract}

Key words Moral development, Ethics, Bioethics, Higher education, Training in human resources
Resumo Trata-se de pesquisa que objetivou analisar a dimensão ética da formação de profissionais de saúde, mais especificamente de Odontologia. Foram realizadas entrevistas com docentes, observações de atividades acadêmicas e grupos focais com alunos de dois cursos de graduação. A análise dos dados revelou elementos do currículo oculto que influenciam a dimensão ética da formação. Os resultados aqui discutidos apontam diferentes concepções de ética no ambiente acadêmico com o predomínio do entendimento deontológico, cujas consequências no manejo dos conflitos éticos cotidianos demandam atenção. O embasamento no senso comum e a ausência de intencionalidade do corpo docente com relação à formação ética dos estudantes indicam como imperativa a necessidade de se conhecer os valores que vivenciam, de se entender como ocorre o desenvolvimento moral e de se aproximar de um referencial bioético para fundamentar e instrumentalizar o fazer ético-pedagógico. Conclui-se ser fundamental que individual e coletivamente se assuma a responsabilidade docente quanto à dimensão ética da formação profissional, para que esta seja também uma possibilidade integral do ser humano.

Palavras-chave Desenvolvimento moral, Ética, Bioética, Educação superior, Formação de recursos humanos 


\section{Introdução}

As profissões da saúde passam atualmente pelo processo de reorientação da formação acadêmica em busca de um perfil de egresso mais capacitado a uma assistência humanizada, de alta qualidade e resolutividade. Neste contexto, um desafio central e comum a todas as profissões da saúde envolve a formação ética de seus estudantes para que desenvolvam competências profissionais e, ao mesmo tempo, de cidadãos prudentes, responsáveis e socialmente comprometidos.

Por formação ética, ou melhor, pela dimensão ética da formação profissional, entende-se o ensino/aprendizagem/vivência da ética em bases não deontológicas, compromissado com o desenvolvimento e a realização de valores humanizadores e com a conformação da identidade profissional durante a graduação ${ }^{1}$.

Valores humanizadores são valores morais, componentes fundamentais do mundo humano. Conceitualmente, valor é o caráter objetivo consistente na dignidade positiva ou negativa (desvalor) que reconhecemos quando valoramos algo ou alguém. Em outras palavras, são qualidades reais das pessoas, das coisas, das ações, das instituições e dos sistemas, que nos permitem analisar o mundo e modificá-lo para que possamos viver nele plenamente como pessoas ${ }^{2}$.

Ortega y Gasset ${ }^{3}$ partia da constatação da universalidade do fenômeno humano de valoração para compreender os valores como qualidades objetivas. Diferentemente dos fatos que percebemos, os valores estimamos e valoramos. São duas faculdades psicológicas distintas (o perceber e o estimar) e fundamentais. A valoração é um processo absolutamente necessário, que realizamos a todo momento, permitindo-nos projetar ações e prever consequências, e que nos caracteriza como seres inevitavelmente morais ${ }^{2,4,5}$.

Assumidos pela ética com o significado de modelo de orientação ou representação orientadora de nossas ações ${ }^{6}$, os valores estão no cerne do processo de desenvolvimento moral, entendido como o processo de valoração de atos, comportamentos e características do indivíduo, tais como a capacidade de refletir sobre aspectos morais e realizar julgamentos pessoais de ordem moral, escolhendo entre o que parece ser certo ou errado, justo ou injusto, bom ou mau. É através do desenvolvimento moral do estudante que a dimensão ética da formação profissional se processa, devendo buscar uma capacidade de raciocínio autônomo que contribua para uma atuação profissional capaz de conviver em uma sociedade democrática e pluralista, e direcionada a buscar relações sociais mais justas e humanizadas ${ }^{1}$. Contudo, a atenção e a deliberação sobre os valores vivenciados, e a educação para o seu manejo razoável e prudente é algo que não se tem feito, pelo menos não de modo suficiente, sendo talvez o maior déficit do nosso sistema educativo ${ }^{5}$.

Considerando que toda profissão possui uma cultura específica e, portanto, valores específicos, o processo de socialização profissional inclui mais do que a educação e o treinamento que ocorrem com o aprendizado direto através do ensino previsto no currículo formal. Inclui as "lições do currículo oculto" que envolvem, principalmente, as influências de todas as relações sociais estabelecidas no processo ensino-aprendizagem, no qual o estudante é sujeito ativo e não um mero objeto a ser moldado pela corporação ${ }^{1}$.

Dessa forma, o processo de socialização profissional passa pelo desenvolvimento moral do estudante que se inicia precocemente na infância (socialização primária), mas que continua durante toda a graduação, abarcando questões e valores relacionados ao mundo da profissão e do trabalho em saúde, e às particularidades da formação na saúde. Na interface destes conceitos, o objeto da presente pesquisa pôde ser delimitado em um marco conceitual ${ }^{7}$, direcionando a busca de estratégias metodológicas que possibilitassem compreender como vem sendo desenvolvida a dimensão ética dos futuros profissionais de saúde e mais especificamente, dos estudantes de Odontologia.

\section{Métodos}

Este estudo descritivo empregou a abordagem qualitativa por ser considerada a mais adequada à compreensão de fenômenos específicos e delimitáveis, mais pelo seu grau de complexidade interna do que por sua expressão quantitativa ${ }^{8}$. Sendo a dimensão ética da formação profissional um objeto essencialmente qualitativo - historicamente construído, complexo, contraditório, inacabado e em permanente transformação -, a opção pelo método qualitativo - capaz de incorporar a questão do significado e da intencionalidade como inerentes aos atos, às relações e às estruturas sociais ${ }^{9}$ - se confirma.

Após aprovação do projeto de pesquisa pelo CEP/UFSC, dois cursos foram selecionados intencionalmente para a coleta de dados, a partir de resultados alcançados em trabalho prévio ${ }^{10}$, 
um público e o outro privado. Seus coordenadores autorizaram a realização da pesquisa nas instituições e os sujeitos convidados a participar consentiram mediante firma de Termo de Consentimento Livre e Esclarecido.

A fim de possibilitar a triangulação dos achados, diferentes técnicas de coletas de dados foram empregadas, sempre delimitadas pelo critério de saturação. Assim, foram realizadas cinco entrevistas semiestruturadas em cada curso, com uma média de 53 minutos de duração. A escolha dos entrevistados adveio da teoria que alimentou a pesquisa bem como da prática investigativa que conduziu a seleção de interlocutores no próprio campo. Das dez pessoas entrevistadas, cinco eram lideranças nos curso - quatro professores e apenas um estudante, e as demais, professores relacionados ao ensino de ética, direta ou indiretamente. $\mathrm{O}$ roteiro de entrevistas continha apenas itens indispensáveis que delineavam o objeto, dandolhe forma e conteúdo, e foi analisado previamente à entrada em campo por dois especialistas que auxiliaram o seu aperfeiçoamento.

Também foram realizados dois grupos focais com oito estudantes do penúltimo e último ano da graduação, um em cada curso. O roteiro preparado para estimular a discussão consistia em um quadro composto por três colunas, correspondentes cada, respectivamente, a valores muito, eventualmente e raramente presentes. Aos estudantes foi solicitado que preenchessem espontaneamente o quadro, pensando nas mais variadas situações que vivenciaram durante o curso. Na sequência, uma lista de valores (elencados a partir de uma síntese das principais tradições éticas ${ }^{7}$ e dos valores livremente citados por 1202 estudantes universitários que participaram de uma pesquisa a esse respeito ${ }^{11}$ ) foi lida, a fim de que os sujeitos pudessem incrementar seu quadro. A partir dessa reflexão, foram estimulados a compartilhar com os demais os valores mais ou menos vivenciados no curso, a partir da lembrança de fatos e sentimentos, promovendo um debate entusiasmado e, ao mesmo tempo, as condições de aprofundamento do tema que a pesquisa necessitava.

Com o objetivo de complementar a coleta de dados, foram realizadas observações diretas das atividades acadêmicas. Foram 10 os relatórios de observações realizadas nos dois cursos: quatro em aulas teóricas, três em práticas, um em atividade de recepção a calouros e outros dois com observações livres do ambiente, conversas informais e sobre os momentos de saída dos campos de pesquisa. Tal tarefa exigiu um prepa- ro no sentido de se observar tudo que se relacionasse com o objeto, incluindo questões sobre como a dimensão ética da formação profissional se concretiza na prática acadêmica, como é desenvolvida, quais as incongruências entre o que os sujeitos dizem e o que fazem, como se dão as relações de hierarquia entre professores e estudantes, os diálogos, as situações de conflitos, o clima institucional etc. Este preparo incluiu a formulação de um roteiro de observação para o registro adequado das informações relevantes.

As entrevistas e os grupos focais foram gravados e posteriormente transcritos. A este material, juntaram-se as notas do diário de campo da pesquisa e os quadros dos grupos focais, constituindo assim o corpus de dados para análise, realizada com emprego do software Atlas.ti ${ }^{\circledR}$. Uma vez inseridos no programa, os dados foram ordenados, categorizados e reordenados de acordo com as categorias iniciais, gerando categorias temáticas. Por fim, foram analisados à luz das referências teóricas pertinentes.

\section{Resultados e discussão}

\section{Modos de entender a ética na formação profissional}

Os dados coletados evidenciaram a percepção da ética sob dois enfoques que refletem distintas concepções que coexistem, ainda que uma delas seja a predominante, a saber, a da ética que embasa a Deontologia. Deontos significa "deve ser" e o que deve ser é um dever. Trata-se, portanto, da ética dos deveres - uma ética normativa, prescritiva, que determina o que deve ser feito. Com essa fundamentação, a ética é entendida como fazer o bem e, por conseguinte, não fazer o mal; fazer o correto; fazer apenas o que é legalmente permitido; obedecer a um código estabelecido; e adotar determinada postura profissional.

Tratar todas as pessoas bem [...] não fazer mal a ninguém [...] trabalhar até pelo seu direito e não extrapolá-lo [...] não sobretratar... (entrevista com professor 1 do curso público).

... a gente tem conversado sobre questões éticas, sobre postura do cirurgião-dentista, sobre as formas corretas de lidar com os problemas [...] se você não faz nada para mudar o pensamento das pessoas sobre a cola, elas vão continuar colando porque é um crime pequeno [...] na verdade não é, porque se você faz isso no pequeno você provavelmente vai fazer isso no grande também... (entrevista com professor 1 do curso privado). 
A mesma concepção de ética foi observada por Lima e Souza ${ }^{12}$ entre estudantes concluintes de Odontologia que definiram o profissional ético como "aquele que cumpre com seus deveres, age com bom-senso e é justo perante os pacientes, funcionários e colegas".

O referencial deontológico que embasa este entendimento se fundamenta na existência do correto. Ser ético seria seguir o correto. Mas quando se sabe o que é correto e, portanto, o que deve ser feito, é preciso apenas obedecer, tanto que ao se descumprir o determinado como correto nos códigos profissionais, pode-se ser penalizado. Percebe-se, portanto, que as normas vêm de fora, que são externas ao sujeito.

A Deontologia surgiu em um momento da história da filosofia moderna em que vigorava a teoria kantiana dos imperativos categóricos, segundo a qual, juízos morais poderiam ser definidos a partir da razão humana e apenas dela, como se tratassem apenas de fatos. Eram o fundamento das éticas típicas do século XVIII chamadas de “éticas deontológicas”. Com a evolução do pensamento filosófico, foi ficando evidente que a mente humana não é capaz de esgotar toda a riqueza da realidade e que, por isso, quando se diz que algo é verdadeiro, pode se estar dizendo a verdade, mas não toda a verdade. Em realidade, está se dando uma opinião. A “crise da razão" veio à tona exatamente ao se perceber que a maioria das verdades não são absolutas e, em não sendo, uma maneira de se enriquecer a perspectiva sobre determinada realidade, incrementando sua veracidade é trocar opiniões, dialogar e deliberar. Assim, os juízos morais deixaram de ser considerados apodícticos (certos, verdadeiros, demonstráveis, irrefutáveis) e passaram a ser considerados dialéticos (opinativos, prováveis, não demonstráveis). Mais do que derivar de princípios, os juízos morais devem levar também em consideração as circunstâncias e as consequências, para reduzir as incertezas da realidade. Desta forma, a tomada de decisões razoáveis em situações incertas em busca da melhor decisão possível tornou-se o fundamento das éticas típicas do século XX, as "éticas da responsabilidade" 4 .

Com este embasamento podemos compreender a outra forma percebida nos cursos de se conceber a ética, qual seja capacidade de reflexão e ponderação; exercício da autocrítica; desenvolvimento de valores humanizadores; busca pela excelência; e promoção do bem para além da obrigação individual.

Tentar fazer o melhor possível. Não só deixar de fazer o mal, mas de tentar melhorar, mesmo que aquilo não seja da sua alçada [...] A gente tenta muito trabalhar esses valores com os alunos, do respeito, da paciência (entrevista com professor 2 do curso público).

Essa postura reflexiva diante de questões que emergem no cotidiano [...] não em discussão do que é certo ou errado, mas de alguns elementos do que é que deve ser preservado, no caso da saúde... da dignidade [...] ética em relação ao atendimento com seres humanos [...] responsabilidade com o paciente [...] ter um diálogo... tornar o paciente um coparticipante no tratamento... Para começar a ter a sensibilidade social e [...] mudar a situação desse país que é terrível... (entrevista com o professor 3 do curso privado).

Pode-se perceber o contraponto entre as duas formas de conceber a ética: de um lado a que tem como base a Deontologia, que manda agir a partir de uma resposta conhecida (acerca do verdadeiro, correto ou bom) - a qual denominamos aqui de Ética Profissional, uma vez que constitui a forma mais tradicional da ética nas profissões; e do outro lado, a ética que tem como base a reflexão pessoal e a autocrítica, o exercício de ouvir e dialogar para compreender, que manda agir com prudência quando não se sabe qual decisão seria melhor, como ocorre nas situações de conflito ético, que surgem sempre que dois valores se opõem.

Diante de conflitos éticos, não há como buscar a solução correta, pois não se sabe qual(is) $\operatorname{seria}(\mathrm{m})$ e nem ao menos se existe $(\mathrm{m})$. O possível é buscar a solução mais prudente ${ }^{4}$. A esta ética - cujas normas não vêm de fora, mas da reflexão interna - denominamos aqui Bioética, por ser uma postura que se aproxima desta disciplina que tem construído um novo paradigma intelectual e cultural para a análise dos confrontos entre valores e fatos.

Os sujeitos de pesquisa sabem que há uma diferença entre Deontologia e Bioética, mas ao discutir conflitos éticos no cotidiano acadêmico, abordam problemas conceitualmente diferentes como se compartilhassem um único referencial. $\mathrm{Na}$ realidade, a maioria dos problemas identificados pelos professores pertence ao domínio da Ética Profissional.

A gente não tem dificuldades de problemas éticos profissionais [...] de vez em quando tem um paciente que se sente ultrajado, humilhado ou que não se sente respeitado, ou que não foi chamado, ou que o tratamento dele está demorando demais, mas isso é assim... de cinco mil pessoas/ano, dois ou três [...]. Alguns dilemas éticos que a gente tem no diaa-dia: a questão da cola na sala de aula [...] plágio 
em TCC [...] o aluno que traz o manequim do colega e apresenta como seu [...] forçar tipo de tratamento para cumprir as metas [...] biossegurança ... (entrevista com professor 1 do curso privado).

Se a percepção de ética se restringe à atitude de se fazer o que é correto, o entendimento do que seriam conflitos éticos se torna limitado, podendo ser interpretado como problemas de relacionamento interpessoal ou de ordem técnica ou ainda, jurídica. Esta indiferenciação entre as concepções de "Ética Profissional" e de "Bioética" contribui negativamente na formação dos estudantes ao perpetuar o predomínio da primeira e manter a segunda invisibilizada. Mesmo quando o curso considera importante trabalhar a formação ética de seus estudantes, o faz basicamente segundo a concepção da Ética Profissional.

A análise do que deveria ser o Termo de Consentimento Livre e Esclarecido nos prontuários odontológicos das clínicas corrobora tal interpretação. Na realidade, os documentos existentes são autorizações que vinculam a assinatura com o acesso ao tratamento ${ }^{13}$, mas como frequentemente o serviço oferecido é considerado única opção de acesso a atendimento, a obrigatoriedade da assinatura já invalida os documentos. Ademais, o conteúdo normalizador e de explícita intenção de proteção de apenas uma das partes também corrompe seu valor supostamente ético.

... concordo com toda a orientação seguida, para fins didáticos, de diagnóstico elou tratamento. Concordo também que radiografias, fotografias, modelos [...] resultados de exames [...] constituem propriedade exclusiva da [nome da faculdade], à qual dou plenos direitos de retenção, deslocamento e uso para quaisquer fins de ensino e de divulgação [...] respeitando os respectivos códigos de ética [...]. Firmo o presente documento, que poderá, inclusive, ser usado como atestado em decisões judiciais [documento do curso privado].

A assiduidade e pontualidade do paciente são fundamentais [...] Os casos clinicos de interesse didático poderão ser registrados [...] resguardando a identidade [...] Em caso de acidente pérfuro-cortante, comprometo-me a seguir todas as normas [...] permitindo a realização de exames laboratoriais que se fizerem necessários [...] após esclarecido sobre o tratamento a ser realizado e dos riscos relativos ao mesmo, aceito o que me for indicado, responsabilizando-me pelo que possa ocorrer $d u$ rante o referido tratamento (documento do curso público).

Diversos problemas éticos e legais estão presentes nestes documentos, entre os quais, a atribuição da posse de documentos e materiais que dizem respeito à saúde dos sujeitos exclusivamente à instituição, uma vez que esta é apenas a fiel depositária destes materiais, sendo obrigatória a permissão ao "acesso a qualquer momento, do paciente ou terceiro por ele autorizado, a seu prontuário e aos dados nele registrados..."14. Também a autorização antecipada da realização de exames laboratoriais (como seria o teste para detectar HIV no caso de acidentes perfuro-cortantes) é inaceitável, ferindo a própria Constituição Federal que assegura no art. $5^{\circ}$, em seu inciso $\mathrm{X}$, que "são invioláveis a intimidade, a vida privada, a honra e a imagem das pessoas..."15.

Vincular a autorização para atendimento clínico com aquela para uso didático, de pesquisa e de divulgação (publicidade institucional?) também pode ser considerado eticamente inadequado pela coerção que pode representar ao paciente e pela ausência de dados concretos sobre o futuro uso de suas informações ou materiais. Como denunciaram Gonçalves e Verdi ${ }^{13}$, caracterizam uma das situações de desrespeito à autonomia do paciente observadas em clínicas odontológicas de ensino.

Da mesma forma, o aceite antecipado do tratamento que lhe será indicado sem incluir expressamente a possibilidade de escolha entre diferentes alternativas, sem lhe garantir a continuidade do atendimento mediante recusa a determinados procedimentos, bem como a isenção de responsabilidade profissional sobre o tratamento a ser realizado ("responsabilizando-me pelo que possa ocorrer”) também são elementos que comprometem esses documentos.

A decisão de uma pessoa de procurar assistência em uma instituição de ensino não concede nem implica em acesso irrestrito ao seu corpo. No entanto, os limites desse acesso frequentemente não são respeitados, tornando-se evidente a situação de vulnerabilidade a que os sujeitos são submetidos. Além disso, o serviço que recebem costuma ser caracterizado como caridade e não como direito que é no caso das instituições publicamente financiadas ${ }^{13}$.

Embora alguns docentes demonstrem preocupação com o emprego destas autorizações para $\mathrm{o}$ atendimento, de um modo em geral, atribui-se a elas pouca atenção. Como reconhecem...

A preocupação é até mais legal do que ética [...] na verdade o termo de consentimento hoje ele é exigido, mas ainda há uma falta de compreensão da necessidade dele. Sempre a base é legal (entrevista com professor 5 do curso privado).

A maior visibilidade da Ética Profissional pode ser historicamente compreendida pelas di- 
ferentes formas e momentos de sua inserção nos cursos da área da saúde. Especificamente na Odontologia, o conteúdo forense, fortemente vinculado ao deontológico estão presentes nos seus currículos desde $1962^{16}$. Somente a partir de 1996, com a publicação da Resolução 196 do Conselho Nacional de Saúde, orientando a criação dos primeiros Comitês de Ética em Pesquisa no ano seguinte, a ética passou a ser mais discutida sob outro enfoque no meio acadêmico. A presença de cursos de pós-graduação e as atividades de iniciação científica favoreceram o estudo da ética em pesquisa com seres humanos nos cursos de graduação, antes que a Bioética se fizesse presente, o que tem acontecido ainda mais recentemente e de forma incipiente.

Eu acho que é mais a postura do professor, como ele lida, como ele é certo com o que ele atribui, com o que ele coloca, do que propriamente a disciplina. Ela pode suscitar o debate, pode sensibilizar, pode despertar, mas o professor é fundamental (entrevista com professor 4 do curso privado).

A ética não é uma coisa que se fala, é uma coisa que se faz. Se você fala uma coisa e faz outra, mesmo que o seu discurso seja lindo você não é ética. Acho que a maioria (dos professores) vai mais ou menos na mesma direção (entrevista com professor 1 do curso privado).

Os docentes têm razão quanto ao fato da ética ser prática e quanto ao fato das atitudes e comportamentos docentes serem fundamentais para a formação ética dos estudantes. Realmente se observou que esta é a forma principal de lidarem com a dimensão ética da formação profissional. O que não ficou tão evidente é que essa atuação seja plenamente consciente e, ainda mais, que seja intencional. E, em não sendo intencional, o cuidado com a formação ética dos estudantes não vem sendo refletido, planejado, nem avaliado.

É mais de currículo oculto [...]. A gente não fala. Não existe lá [no plano de ensino] ou será que talvez exista e eu não lembre? [risadas] (entrevista com professor 3 do curso privado).

[A bioética] não é uma coisa que esteja fazendo falta porque eu acho que todo mundo tem também, de uma forma empírica, mas todo mundo tenta fazer, sabe? (entrevista com professor 2 do curso público).

De um modo geral, os professores acreditam que basta o bom exemplo, derivado do bom senso de cada docente. Mas o senso comum não é adequado e muito menos suficiente para o embasamento de algo tão importante quanto o desenvolvimento moral dos estudantes e o ensino do manejo de conflitos éticos cotidianos. É preciso ir à busca do conhecimento que falta ao corpo docente para melhor trabalhar a dimensão ética da formação profissional. Mais que isto, é preciso investir no conhecimento e na formação ética de nossos docentes, pois como afirmou um deles,

Para trabalhar com ética você tem que ter ética [...] Eu não acho que é bem trabalhado ainda [...] sinto a necessidade de ter uma discussão, de chamar um professor da filosofia. Eu acho que os professores precisam de formação ética sim, inclusive eu [risos] (entrevista com professor 4 do curso privado).

Percebe-se, portanto, a necessidade do corpo docente se aproximar dos conhecimentos de ética, incluindo as suas diferentes formas de concepção e de inserção no currículo odontológico para que o senso comum deixe de embasar o seu fazer. Para tanto, capacitações em Bioética podem ser de grande valia, desde que não a limitem às questões da ética em pesquisa com seres humanos, como frequentemente se observa em cursos de pós-graduação stricto-sensu, lócus privilegiado de formação docente.

Ao mesmo tempo, é preciso promover o aperfeiçoamento humanístico dos próprios docentes, para que, mais conscientes da importância dos valores na práxis e da possibilidade de intervenção no desenvolvimento moral dos estudantes, atuem como bons modelos profissionais e contribuam para transformar as práticas de ensino em humanizadas e humanizadoras. Capacitados, conscientizados e valorizados, os docentes estarão mais preparados a imprimir aos conteúdos que ensinam o caráter ético que contribuirá com a formação dos profissionais e cidadãos de que a sociedade necessita.

\section{Valores e desenvolvimento moral no cerne do processo de formação ética}

A formação ética na escola [...] pode contribuir, mas ela não é o centro não. A família com certeza [...] Talvez a universidade seja o local de por foguinho na potência, mas não são nesses quatros anos que a gente vai formar uma pessoa de ética para a vida inteira, não [...] nós temos os limites também [...] quem não vem despertado... Aqui é um espaço propício para isso, justamente porque é um lugar que discute coisas que não se discute em outros lugares [...] então sinceramente é até dialético, é sim e não (entrevista com professor 4 do curso privado).

A fala do docente indica as potencialidades e os limites do processo de socialização profissional frente ao primário. De fato, as experiências 
vividas por um indivíduo desde a infância precoce são elementos que participam da construção identitária de uma forma muito significativa, especialmente por seus componentes afetivos e psicológicos, de modo que tendem a persistir ao longo do tempo. Assim, o processo da socialização secundária precisa lidar com uma personalidade formada e um mundo interiorizado, o que representa um problema fundamental ${ }^{17}$, constatado por todos aqueles que participam da formação profissional. É o que se quer dizer quando se afirma que "há coisas que vêm de berço". Não que não seja verdade, mas o problema deste argumento é o imobilismo que costuma lhe acompanhar, como se nada pudesse ser feito. Mas justamente pelo contrário, o professor que também é educador, percebe nas dificuldades o desafio e a necessidade de instigar mudanças.

Não se pretende afirmar que seja tarefa simples, mas que é possível contribuir. Da universidade se espera o desenvolvimento social e este depende dos resultados do processo de socialização profissional. Está certo que a socialização secundária não transforma os estudantes cujas interiorizações primárias sejam incoerentes com as novas, pois como afirmavam Berger e Luckmann ${ }^{17}$, "são necessários graves choques no curso da vida para desintegrar a maciça realidade interiorizada na primeira infância”. O que se pode fazer é promover o desenvolvimento moral dos estudantes - a maioria ainda adolescente em transição para a vida adulta. É com o estímulo ao seu amadurecimento que se pode contribuir, inclusive para a transformação social.

Eu vejo os alunos como muito imaturos [...] vamos pensar numa formação mais ampla... há uma minoria que tem uma formação de família, uma formação ética importante, consolidada, que sabem os valores... Mas em geral os jovens perderam os valores! (entrevista com professor 4 do curso privado).

Se for inegável que uma parcela dos estudantes chega ao processo de socialização secundária com uma educação moral insatisfatória, é fundamental que as faculdades, se não capazes de transformá-los, ao menos, não validem nem piorem esta carência ao apresentar modelos inadequados de atuação ética ou ao negligenciar a sua tarefa ético-pedagógica. Por outro lado, a parcela de estudantes que traz do processo de socialização primária a semente da reflexão ética precisa encontrar na socialização profissional modelos coerentes com esta primeira formação que a reforcem e a solidifiquem, promovendo seu desenvolvimento moral.
Esse processo se dá na vivência de valores, incluindo os compartilhados no ambiente acadêmico. No Quadro 1, apresentam-se os resultados agrupados segundo a presença mais ou menos significativa no cotidiano dos estudantes.

Dentre os valores muito presentes vale destacar o valor da estética, apontada como "a cara da Odontologia” e o prestígio. O mesmo aconteceu com os valores responsabilidade e compromisso - tanto em relação aos exigidos dos estudantes, quanto aos demonstrados pelos docentes - assim como o valor respeito, referenciado nas relações interpessoais, dos estudantes por seus professores e o exigido por estes, em relação aos pacientes. Contudo, cabe mencionar as nuances paternalistas deste respeito em relação aos docentes e o seu caráter deontológico em relação aos pacientes se quisermos compreender os significados a ele verdadeiramente atribuídos ${ }^{7}$.

Chama atenção também a inclusão do sentimento de vínculo e de pertencimento como muito presentes, mas não no sentido de vínculo cívico com os concidadãos e com qualquer ser humano no mundo ${ }^{18}$, e sim de vínculo entre os estudantes e de pertencimento à profissão, suge-

Quadro 1. Presença dos valores no cotidiano dos estudantes.

\begin{tabular}{|l|}
\hline \multicolumn{1}{|c|}{ Valores muito presentes } \\
\hline . Felicidade, paz, vida, saúde, amizade, amor \\
. Estética, prestígio \\
. Responsabilidade, compromisso, seriedade \\
. Dignidade da vida humana, respeito, não \\
discriminação \\
. Sentimento de vínculo, sentimento de \\
pertencimento, cidadania \\
. Honestidade, lealdade \\
\hline \multicolumn{1}{|c|}{ Valores eventualmente presentes } \\
\hline $\begin{array}{l}\text {. Prudência, ponderação, diligência } \\
\text {. Prazer, bem-estar, esperança } \\
\text {. Igualdade, solidariedade, beneficência } \\
\text {. Diálogo, empatia, compreensão } \\
\text {. Engajamento, busca pelo conhecimento } \\
\text {. Estabilidade econômica } \\
\text {. Autonomia dos pacientes }\end{array}$ \\
\hline \multicolumn{1}{|c|}{ Valores raramente presentes } \\
\hline . Tolerância, liberdade, autonomia do estudante \\
- Justiça, realismo
\end{tabular}


rindo um processo de socialização profissional bem encaminhado que remete aos atributos sociológicos usados como definidores das profissões, como a identificação intrapares e a noção de coletividade ${ }^{19}$.

Em relação aos valores eventualmente presentes, a inclusão da prudência, da ponderação, da diligência, do diálogo, da empatia e da compreensão, tão importantes para uma atuação éti$\mathrm{ca}$, indica a necessidade de serem muito mais vivenciados no processo de formação profissional, o que poderia ser realizado pela inclusão no currículo acadêmico de estratégias que visem o manejo de problemas éticos, por exemplo. Do mesmo modo, a igualdade, a solidariedade, a beneficência e o engajamento precisam ser mais vivenciados na socialização profissional se quisermos a formação de futuros profissionais que sejam também cidadãos comprometidos.

Neste mesmo sentido, Divaris et al. ${ }^{20}$ relatam que, sob a perspectiva dos estudantes, os valores compartilhados no ambiente acadêmico são tão ou mais importantes que o conteúdo educacional, o que implica que as relações entre o curso, o corpo docente e o discente devem ser de compreensão, cooperação, disposição e tolerância. No entanto, observaram que os estudantes de Odontologia com frequência descrevem o ambiente acadêmico como hostil ou ameaçador.

A busca pelo conhecimento classificada como eventualmente presente surpreende, afinal são estudantes em pleno processo de formação. Da mesma forma, a autonomia do paciente, embora este valor tenha sido referendado pela dos estudantes como raramente presente, pois como poderiam estes prezar pela dos usuários dos seus serviços se, conforme observado na coleta de dados, são pouco estimulados a desenvolver a sua própria? Este é o tipo de aprendizado que só se torna realidade caso vivenciado, ou seja, somente uma atuação pedagógica menos paternalista, mais justa e democrática, que incentive a liberdade e o autoconhecimento dos estudantes, que seja mais tolerante e flexível, poderá promover uma maior autonomia também do sujeito em atendimento na relação clínica ${ }^{7}$.

Por fim, a indicação dos valores justiça e liberdade como raramente presentes deve também ser observada com preocupação, pois dificilmente serão os futuros profissionais agentes de transformação da realidade social se quase não vivenciam tais valores. Da mesma forma o realismo, que poderá ser muito mais vivenciado se os cursos investirem na integração ensino - serviço - gestão - controle social, o que constitui uma demanda premente nos cursos da saúde, reclamada inclusive pelos estudantes.

- Quais valores colocaram como raramente presentes? (Entrevistadora)

- eu botei realismo, porque as coisas aqui são utópicas às vezes. Querer que qualquer restauração seja feita com isolamento absoluto. Claro, isso tem que ser passado pra gente, mas tem que pelo menos ser falado ou dito como seria se estivesse lá fora e não tivesse o isolamento.

- a gente tá aprendendo uma coisa que é totalmente correta como no livro e quando chega lá fora, como na experiência do posto de saúde assistindo um dentista, meu Deus do céu, é totalmente diferente! (grupo focal no curso público).

Já o discurso docente revelou como valores mais cultivados nos cursos a busca pelo conhecimento por parte dos estudantes, a humanização em relação ao atendimento clínico, incluindo o respeito e o bom relacionamento entre todos os envolvidos, o companheirismo entre os docentes, a cooperação entre os estudantes e o desenvolvimento das competências profissionais.

Um dos valores que eles mais prezam é a competência técnica mesmo... Não é só do ponto de vista de atendimento clínico não, por exemplo, quando um aluno sabe formular bem um projeto ele é muito valorizado, quando ele tem uma visão crítica do mundo e quando ele tem a capacidade de achar soluções [...]. Do ponto de vista do aluno [...] a competência técnica do professor para o ensino é um valor [...] a relação do professor de afinidade com os alunos, a capacidade de compreender suas dificuldades... (entrevista com professor 2 do curso privado).

Percebe-se, portanto, uma disparidade entre os valores mais presentes sob o ponto de vista acadêmico e o docente, o que alerta para a necessidade dos cursos conhecerem o que pensam e como se sentem seus estudantes. Além da inclusão dos valores menos presentes, Martínez et al. ${ }^{21}$ lembram que as faculdades devem primar também pela presença de valores como a seriedade, a dedicação, a crítica, a autocrítica e a superação pessoal perante as dificuldades inerentes ao processo ensino-aprendizagem. Tais valores favorecem a aprendizagem ética, pois contribuem com a formação do caráter intelectual e humanista do estudante, ao aproximá-lo dos problemas do ser humano enquanto tal, acompanhado de dúvidas, sentimentos e intuições, e não simplesmente como futuros profissionais. Além disso, referendam a importância do respeito e do incentivo à autonomia do estudante, da valorização do diálogo e da compreensão como a forma legítima 


\section{Considerações finais}

A atenção com os valores vivenciados pelos estudantes no decorrer do processo de socialização profissional e o planejamento de estratégias que otimizem o seu desenvolvimento moral constitui a forma mais direta de atuação na dimensão ética da formação profissional. Mais do que a inclusão de novas ações ou a realização de mudanças no currículo formal, o tratamento pedagógico do ético no âmbito universitário coloca como desafio a reorientação do fazer dos sujeitos, o que implica fundamentalmente em uma mudança de perspectiva do corpo docente em relação ao que se considera desejável enquanto formação universitária.

Neste sentido, a reorientação do processo formativo consistiria no estabelecimento de relações entre os objetivos éticos da aprendizagem e os recursos, as estratégias e as técnicas disponíveis para tanto, de modo que se possam identificar entre estas relações, aquelas que são necessárias ao desenvolvimento moral dos estudantes, priorizando-as. Trata-se de aproveitar os conteúdos próprios de aprendizagem de cada profissão e as situações naturais e corriqueiras da vida acadêmica para promover a construção da autonomia moral do estudante; de integrar ao processo modelos que favoreçam estes aprendizados frequentemente não contemplados pelos processos de aprendizagem social e de imitação que ocorrem na socialização profissional; de aumentar a densidade cultural dos estudantes pela inclusão e valorização de temas que possuam caráter ético e de conhecimentos que estimulem o comprometimento com projetos sociais coletivos; e ainda, de reorganizar ou recriar cenários pedagógicos, pois nem todas as estratégias de ensino-aprendizado são adequadas a uma aprendizagem ética ${ }^{21}$.

Também a inclusão de novos temas que possuam um caráter ético, como pode ser feito pela introdução de disciplinas de Bioética nos cursos de graduação, deve ser estimulada. A literatura sobre o ensino da Bioética tem crescido na última década, havendo um consenso de que a ética e a Bioética devem ser assumidas como temas transversais na formação profissional, uma vez que permeiam todo o aprendizado profissional. Assim, a inserção de uma disciplina específica de Bioética não deveria ser pontual no currículo, desarticulada das demais, mas representar o núcleo de um projeto pedagógico de sensibilização ética, apoiado e respaldado pelas outras, através do comprometimento de todo o corpo docente em compartilhar esta tarefa.

Cabe lembrar que no processo educativo que visa à formação integral do ser humano, os objetivos diretamente abordáveis são os relacionados aos conhecimentos e habilidades, mas que a sua finalidade é o aperfeiçoamento das atitudes e do caráter ${ }^{4}$, em outros termos, o desenvolvimento moral do estudante. Daí o entendimento que disciplinas de Bioética não são responsáveis exatamente pelo ensino da ética, mas pelo aprimoramento ético-humanístico dos futuros profissionais. Sua atuação deve pautar-se pela instrumentalização dos estudantes para a reflexão crítica, inclusive e, principalmente, acerca de si e das consequências de suas ações sobre os demais.

Evidentemente, isto requer uma adequada fundamentação teórico-metodológica e o emprego de estratégias apropriadas, preferencialmente problematizadoras e interdisciplinares em pequenos grupos de estudantes. Uma destas metodologias é o método deliberativo ${ }^{22}$ - um método de análise de conflitos éticos, mas que se constitui em um processo de autoeducação e autoanálise. Sendo capaz de colaborar com a educação em valores, com a capacidade de escuta, de diálogo e de compreensão e, consequentemente, com o próprio processo de desenvolvimento moral, pode ser recomendado para os docentes que já se saibam e se sintam responsáveis pela dimensão ética da formação dos futuros profissionais. 


\section{Colaboradores}

M Finkler idealizou a pesquisa, coletou e analisou os dados e redigiu o trabalho. JC Caetano e FRS Ramos orientaram a pesquisa e aprovaram a redação final do artigo.

\section{Agradecimentos}

A CAPES pela bolsa de Doutorado com Estágio no Exterior e a todos os cursos, seus professores e estudantes que participaram da pesquisa.

\section{Referências}

1. Rego S. A Formação Ética dos Médicos. Rio de Janeiro: Fiocruz; 2003.

2. Cortina A. Cidadãos do mundo. São Paulo: Loyola; 2005.

3. Ortega y Gasset J. Introducción a una estimativa: ¿Qué son los valores? Madrid: Encuentro; 2004.

4. Gracia D. Fundamentación y ensenãnza de la bioética. 2a Edición. Bogotá: El Búho; 2000.

5. Gracia D. Como arqueros al blanco: estudios de bioética. Madrid: Triacastela; 2004.

6. Höffe O. Valores em instituições democráticas de ensino. Educ Soc 2004; 25(87):463-479.

7. Finkler M. Formação ética na graduação em Odontologia: realidades e desafios [tese]. Florianópolis: Universidade Federal de Santa Catarina; 2009.

8. Minayo MCS, Sanchez O. Quantitativo-qualitativo. Cad Saude Publica 1993; 9(3):239-262.

9. Minayo MCS. O desafio do conhecimento. São Paulo: Hucitec; 1999.

10. Finkler M, Caetano JC, Ramos FR. A dimensão ética da formação profissional em saúde: estudo de caso com cursos de graduação em odontologia. Cien Saude Colet 2011; 16(11):4481-4492.

11. Mamede-Neves MA, Vidal F, Wilmer C. Problemas e valores apontados por jovens universitários pertencentes a "sociedades emergentes": um estudo sobre a Barra da Tijuca, Rio de Janeiro. ALCEU 2003; 4(7):164-195.

12. Lima ENA, Souza ECF. Percepção sobre ética e humanização na formação odontológica. RGO 2010; 58(2):231-238.

13. Gonçalves ER, Verdi M. Os problemas éticos no atendimento a pacientes na clínica odontológica de ensino. Cien Saude Colet 2007; 12(3):755-764.
14. Brasil. Ministério da Saúde (MS). Carta dos direitos dos usuários da saúde. Brasília: MS; 2006.

15. Brasil. Constituição da República Federativa do Brasil de 1988. Diário Oficial da União 1988; 5 out.

16. Fernandes-Neto AJ. A Evolução dos cursos de Odontologia no Brasil. Rev. ABENO 2002; 2(1):55-56.

17. Berger PL, Luckmann T. A construção social da realidade. Petrópolis: Vozes; 1985.

18. Cortina A. La educación del hombre y del ciudadano. Rev Iberoamericana de Educación 1995; 7:41-63.

19. Machado MH. Sociologia das profissões: uma contribuição ao debate teórico. In: Machado MH, organizador. Profissões de saúde. Rio de Janeiro: Fiocruz; 1995.

20. Divaris K, Barlow PJ, Chendea SA, Cheong WS, Dounis A, Dragan IF, Hamlin J, Hosseinzadeh L, Kuin D, Mitrirattanakul S, Mo'nes M, Molnar N, Perryer G, Pickup J, Raval N, Shanahan D, Songpaisan Y, Taneva E, Yaghoub-Zadeh S, West K, Vrazic D. The academic environment: the students' perspective. Eur J Dent Educ 2008; 12 (Sup. 1):120-130.

21. Martínez MM, Estrada MRB, Bara FE. La universidad como espacio de aprendizaje ético. Rev IberoAmericana de Educação 2002; 29:14-43.

22. Gracia D. La deliberación moral: el método de la ética clínica. Med Clin 2001; 10(117):18-23.

Artigo apresentado em 16/03/2012

Aprovado em 14/05/2012

Versão final apresentada em 29/05/2012 